\title{
Aging and immunoglobulin isotype patterns in oral tolerance
}

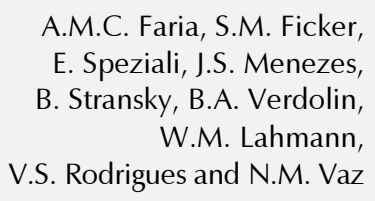

A.M.C. Faria, S.M. Ficker,

E. Speziali, J.S. Menezes,

B. Stransky, B.A. Verdolin, W.M. Lahmann,

V.S. Rodrigues and N.M. Vaz

Departamento de Bioquímica e Imunologia, Instituto de Ciências Biológicas, Universidade Federal de Minas Gerais, Belo Horizonte, MG, Brasil
Correspondence

A.M.C. Faria

Departamento de Bioquímica e

Imunologia, ICB, UFMG

Av. Antônio Carlos, 6627

31270-901 Belo Horizonte, MG

Brasil

Presented at the International

Meeting on Cytokines, Angra dos

Reis, RJ, Brasil, November 24-28, 1996.

Research supported by FAPEMIG (No. 2501/96), PRPq and CNPq (No. 53.0349/93-0).

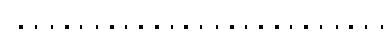

Received September 4, 1997 Accepted November 6, 1997 ....................

\section{Abstract}

In the present review we address oral tolerance as an important biological phenomenon and discuss how it is affected by aging. Other factors such as frequency of feeding and previous digestion of the antigen also seem to influence the establishment of oral tolerance. We also analyze immunoglobulin isotypes of specific antibodies formed by tolerant and immunized animals of different ages submitted to different conditions of oral antigen administration. Isotypic patterns were studied as a parameter for assessing the pathways of B and T cell interactions leading to antibody production.

Key words

- Oral tolerance

- Aging

- Isotypes

- Gut

- Mucosa

\section{Feeding and immunological activities}

Feeding is the major and most frequent occasion on which the organism contacts foreign proteins and, potentially, the major source of triggering immunological activities. Through idiotype-anti-idiotype connections, events initiated in the gut may influence all immunological phenomena, regardless of their origin. For example, effective vaccination against trachoma has been recently achieved by oral exposure to an antiidiotypic antibody (1), showing that the gut provides a direct and effective access to the immune system by a physiological route.

Two misconceptions cause this evidence to be pratically ignored. First, ingested antigenic molecules are thought to be totally digested and thus devoid of immunological relevance. This is simply incorrect and is contradicted by many experimental observations (2). Second, and more importantly, the immune system has been conceptually divided into two systems. Secretory IgA immunoglobulins (sIgA) present on mucosal surfaces react with germs and viruses and may hinder the absorption of antigenic macromolecules. SIgA is mainly produced in local mucosal-associated lymphoid tissues but lymphocytes stimulated at a local mucosal site migrate to other sites of the same mucosa and also to other mucosae $(3,4)$. This suggests the operation of a web of intermucosal cell traffic independent of a more "systemic" immune circuitry. Thus, the organism is seen as doubly protected from antigens in the gut: by digestion and by a "secretory immune system" or "common mucosal immune system" (5).

Neither argument is correct: there is a continuous penetration of antigenic material through the gut, mainly during and after feeding (2) and there is a complex interplay of "systemic" and "mucosal-associated" immune phenomena (6-8). 


\section{Different outcomes of oral contacts with antigens}

Although different immunological outcomes may result from oral exposure to antigens, a basic pattern may be understood. Depending on several factors, related to the antigen and/or the organism, oral contacts with antigens may result either in oral tolerance or in its reverse: "local" and/or "systemic" immunization, i.e., circulating antibody formation (9-14). Intermittent feeding of mature or older mice with ovalbumin (Ova), depending on the antigen/strain combination (11), tends to result in serum antibody formation $(12,15)$. However, natural feeding of mice has been shown to result preferentially in oral tolerance to dietary components, especially to proteins repeatedly ingested on several consecutive occasions $(10,16)$.

Oral tolerance is defined as a suppression of the specific immune response to parenteral injections of the antigen previously presented by the oral route $(7,17-19)$. This phenomenon has been reported in a number of animal species, including mice (20), hamsters (21), rats (22), guinea pigs (23), rabbits (24), and humans (25) and can be measured as a decrease in delayed type hypersensitivity (DTH) reaction to the antigen (26) as well as a suppression in specific IgE and $\mathrm{IgG}$ production (27).

Several reports indicate that antigen/strain combination, the nature and dose of antigen (28), the immunological status of the animal (29), genetic factors linked or not to MHC $(11,14)$, age at first oral contact $(15,30,31)$, frequency of exposures and interval between them $(10,12)$ are all factors determining the outcome of oral contacts with antigens.

Herein, we review past evidence and present data on the influence of aging and the rate of antigen intake on oral tolerance. We also analyze the isotypic patterns associated with oral tolerance at different ages and under different experimental conditions.
Immunoglobulin isotypes, aging and oral tolerance

Maturation of mice of different inbred strains to young adulthood - a period arbitrarily defined between 8 and 24 weeks of age - coincides with a marked decrease in their susceptibility to the induction of oral tolerance and a parallel (consequent?) increase in their susceptibility to systemic oral immunization following repeated (intermittent) oral exposures to antigens $(12,15,32,33)$.

Moreau and Gaboriau-Routhiau (34) recently reported induction of oral tolerance to Ova in 20-month-old $\mathrm{C} 3 \mathrm{H} / \mathrm{He}$ mice. However, in other studies using the parenteral route for tolerance induction, a decrease in ease of tolerance induction in aged $\mathrm{BALB} / \mathrm{c}$, C57BL/6 and CBA/CaJ mice $(35,36)$ and a relative inability to induce tolerance in adult NZB and (NZB X NZW) F1 mice (37) have been described. The impairment of tolerance induction seems to affect both $B$ and $T$ cell populations in 6-month-old $\mathrm{BALB} / \mathrm{c}$ mice $(38,39)$.

As shown in Figure 1, there is a marked decrease in the titers of anti-Ova antibody immune responsiveness to Ova (saline-fed groups) of 70-week-old mice when compared to 8- or 25-week-old mice.

The maintenance of oral tolerance is not altered by aging (Table 1). B6D2F1 mice received $20 \mathrm{mg}$ Ova by gavage at 8 weeks of age and were allowed to rest for 62 weeks after which (at 70 weeks) they were tested for serum anti-Ova antibodies. They were then re-immunized with Ova in $\mathrm{Al}(\mathrm{OH})_{3}$, boosted with $10 \mu \mathrm{g}$ Ova after 21 days and bled after 7 days. Animals in all groups increased their anti-Ova antibody titers after the booster but a significant difference between immune and tolerant mice was maintained. Therefore, it seems that aging influences the induction of oral tolerance but not its maintenance. If antigen has already been presented in early adult life, the same animals are able to either respond with high 
titers of anti-Ova antibodies or to recall their previous tolerance status.

Several changes in immunological parameters are observed during aging. $\mathrm{B}$ and $\mathrm{T}$ lymphocytes change in phenotype and repertoire. The ratio of activated $T$ cells (CD45RO) to resting T cells (CD45RA) increases. In mice and humans, the patterns of cytokines secreted by activated $T$ cells change significantly, with a reduction of IL-2, IL-3, and GM-CSF and an increase of IL-4, IL-5, IFN- $\gamma$, IL-6 and IL-10 (40-43). Macrophage production of IL-1 and TNF also changes (44). There is a depression in early signal transduction as well as a reduction in calcium fluxes (45-48) in activated $\mathrm{B}$ and $\mathrm{T}$ lymphocytes in old animals. The levels of dimeric IgA produced in gut lamina propria as well as the number of $\mathrm{CD}^{+} \mathrm{T}$ cells in Peyer's patches are significantly reduced in old animals $(49,50)$.

All of these aging-associated changes can potentially interfere with the operation of the immune system as a whole and systemic phenomena such as tolerance are expected to be altered by senescence. We believe, however, that the discussion on the effect of aging on oral tolerance invokes the very mechanisms responsible for its induction and maintenance (33).

\section{Suppression vs anergy in oral tolerance}

The mechanisms underlying oral tolerance induction and maintenance are still elusive but two proposals have been enthusiastically discussed in the recent literature: clonal anergy and suppression by the differential production of cytokines by specific $\mathrm{T}$ cell clones.

Clonal anergy and clonal deletion are concepts derived from the notion that immune events are necessarily destructive and require mechanisms of contention to circumvent immunological self-destruction. The original suggestion that self-tolerance relies

Table 1 - Maintenance of oral tolerance is not affected by aging

B6D2F1 mice were fed either saline (normal and immune group) or $20 \mathrm{mg}$ Ova (tolerant group) by gavage 7 days before the primary immunization and booster. The normal group was not immunized. The animals were classified as normal, tolerant and immune, and then, allowed to rest for 62 weeks before being boosted again with $10 \mu \mathrm{g}$ Ova ip, $10 \mu \mathrm{g}$ Ova $+1 \mathrm{mg} \mathrm{Al}(\mathrm{OH})_{3}$ and $10 \mu \mathrm{g}$ Ova 7 days apart. Sera were collected 7 days after the last immunization and antibodies were measured by ELISA. ELISA scores and significant differences between tolerant and immune groups were calculated as shown in the legend to Figure $1 .{ }^{*} \mathrm{P}<0.001$ compared to the normal group.

\begin{tabular}{lcrr}
\hline Bleedings & Normal & \multicolumn{1}{c}{ Tolerant } & \multicolumn{1}{c}{ Immune } \\
\hline Pre-booster & $153 \pm 24$ & $189 \pm 62^{*}$ & $3224 \pm 265$ \\
Post-booster & $154 \pm 45$ & $4921 \pm 363^{*}$ & $11386 \pm 304$
\end{tabular}

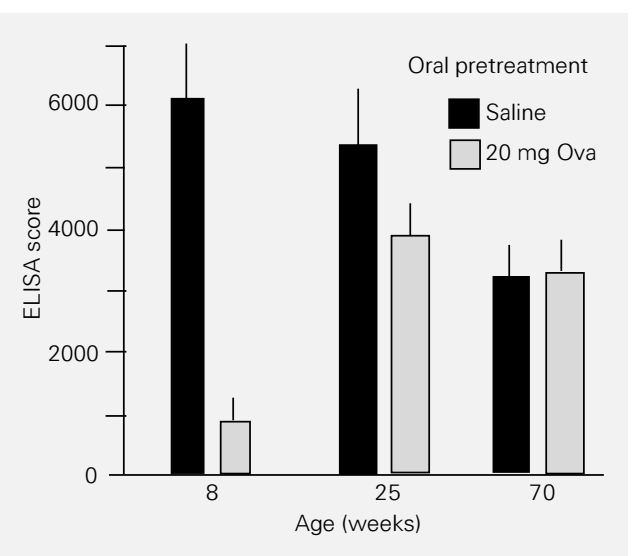

on the deletion of self-reactive (forbidden) lymphocyte clones was supported by the experiments of Brent, Billingham and Medawar on tolerance to allografts (51) and formed the backbone of the clonal selection theory of antibody formation created in the 1960 's by Burnet (52). These initial studies showed that tolerance to allografts could only be achieved early during the neonatal period, suggesting that susceptibility to tolerance is a characteristic of immunologically immature hosts.

A whole array of findings in the last 3035 years have shown these convictions to be basically incorrect. The original Brent, Billingham and Medawar experiments themselves have been repeated (53) and have shown that tolerant animals, far from deleting alloreactive clones, maintain in their bod-
Figure 1 - Immune responses of normal and orally tolerant B6D2F1 mice of different ages. Mice were fed by gavage with either saline or $20 \mathrm{mg}$ ovalbumin (Ova) 7 days before primary ip immunization with $10 \mu \mathrm{g} \mathrm{Ova}+1 \mathrm{mg} \mathrm{Al}(\mathrm{OH})_{3}$. All animals were boosted ip with $10 \mu \mathrm{g}$ Ova 14 days later and sera were collected 7 days after the booster. Anti-Ova antibodies were measured by ELISA and the numbers represent the running sum of absorbance ranging from $1 / 100$ to $1 /$ 3200 in one group ( $N=6-8$ ). Significant differences between Ova-fed and saline-fed groups were calculated by the two-tailed Student $t$ test. A significant difference $(P<0.001)$ between groups was observed only in 8-week-old mice. 
ies a large collection of these clones activated and coexisting with alloantigenic donor cells throughout life.

The phenomenon of oral tolerance represents further strong evidence against these ideas since its induction is diametrically opposite to allograft tolerance. Neonatal mice are not susceptible to oral tolerance (54) but may become susceptible if adoptively transferred with syngeneic lymphocytes from adult donors (55). Thus, this is an active process requiring some degree of systemic organization.

Quite distantly from the neonatal period, the susceptibility to oral tolerance induction also wanes. Maturation to 20-25 weeks of age reduces and living one to one-and-a-half years (50-70 weeks) profoundly impairs the ability of mice to become orally tolerant $(12,15)$. Some of these findings are discussed here (Figure 1). These protracted changes show that immunological activities comprise an ongoing epigenesis which extends far beyond the early phases of ontogenesis (56).

The clonal selection theory tried to explain tolerance based on three main principles: a) immune activity is clone specific; b) tolerance, as opposed to the immune response, represents the absence of such specific immune activity, and c) tolerance, as a negative event, should take place in early life when immunocompetence is not yet completed.

Several recent reports still insist that tolerance must be achieved by the elimination of specific lymphocyte clones but the problems raised by oral tolerance remain to be solved. Anergy is a convenient mechanism for the clonal theory since it provides an explanation for how tolerance, as a clonal negative event, may occur throughout life and not only early in ontogenesis.

Clonal anergy has been described as operative in the thymus as well as at the periphery (57). Apparently, T cell receptor (TCR) occupancy alone, in the absence of a second costimulatory signal provided by antigen- presenting cells (APC), renders mature thymic and peripheral $\mathrm{T}$ lymphocytes anergic (58). This has been shown in normal or cloned $\mathrm{T}$ cells stimulated with peptides presented by chemically modified APC (59), purified MHC class II molecules incorporated into planar lipid membranes (60), stimulation with concanavalin A in the absence of APC (61), or immobilized anti-CD3 antibody (62). In the anergic state, $\mathrm{T}$ cells are rendered refractory to restimulation with APC and $\mathrm{Ag}$, and are unable to secrete IL-2 (58).

It has been suggested that oral tolerance could also be a result of clonal anergy of specific $\mathrm{T}$ cell clones, mostly Th1 cells $(63,64)$. According to these reports, high doses of orally administered antigen result in systemic antigen presentation after antigen passes through the gut and enters the systemic circulation either as intact protein or antigen fragments. Induction of clonal anergy would occur by defective presentation of the protein to the specific $\mathrm{T}$ lymphocytes. Evidence supporting the anergy model includes the fact that spleen cells or lymphocytes isolated from rats made tolerant with myelin basic protein (MBP) did not transfer tolerance to naive recipients. In vitro cell mixing studies have shown that the proliferation of lymphocytes from MBP-sensitized donors was not inhibited by the addition of lymphoid cells from tolerant donors (64). Other reports using Ova as antigen showed that lymphocytes from Ova-tolerant mice did not produce IL-2 or express IL-2R in response to Ova stimulation in vitro (65).

The present results, obtained using a "high dose" feeding protocol (20 mg Ova), again argue against any subtractive mechanism underlying oral tolerance establishment. Susceptibility to oral tolerance may completely disappear in 70-week-old B6D2F1 mice which are among the most susceptible strains to ovalbumin tolerance induction when tested at 7-10 weeks of age. Furthermore, the adoptive transfer of syngeneic spleen cells from young B6D2F1 donors to old recipient mice 
may partially restore their susceptibility to oral tolerance and, reciprocally, adoptive transfer of cells from old donors to young recipients decreases their susceptibility to tolerance. On the other hand, transfer of syngeneic spleen cells from young or neonate (10 days old) BALB/c donors, which are refractory to tolerance induction, to old recipient mice fails to alter the lack of susceptibility to oral tolerance (66).

Therefore, the induction of oral tolerance probably depends on a configuration of cells and molecules present in young but not in old mice $(67,68)$. This configuration transferred by spleen cells seems to provide the plastic connectivity between antibodies and the lymphocytes that animals need to incorporate novel antigens into their immunological activities. Transfer of susceptibility to oral tolerance induction in our model rules out the possibility of any negative mechanism such as anergy or clonal deletion as an operative explanation for oral tolerance.

Interestingly, old mice receiving cells from young mice and orally treated for tolerance induction have an isotypic profile closer to that of young mice and different from that of old mice. This observation suggests that spleen cells were able to transfer not only the susceptibility to oral tolerance induction present in young mice but also its isotypic profile (69).

Suppression does not imply a differential activation of Th1 and Th2 clones

Another hypothesis indicates active suppression by specific $\mathrm{T}$ lymphocytes as a mechanism of oral tolerance establishment.

Early studies have associated the induction of oral tolerance with the activation of suppressor $T$ cells $(20,29,70-72)$, but the nature and the properties of such cells are now disputed. Initially, $\mathrm{CD} 8^{+} \mathrm{T}$ cells were pointed out as the putative suppressor cells (72). Many recent articles still suggest that oral tolerance is due to the activation of $\mathrm{CD}^{+}$suppressor $\mathrm{T}$ cells $(73,74)$. These reports demonstrate that $\mathrm{CD} 8^{+}$lymphocytes can play a regulatory role in a number of immune activities either through classical cytotoxic effects on APC or via the production of cytokines such as IFN- $\gamma$ and TGF- $\beta$. However, other authors have shown that in vivo depletion of $\mathrm{CD}^{+}$cells at the time of feeding had no effect on the induction of oral tolerance, whereas depletion of $\mathrm{CD}^{+}$cells completely abolished the suppression of DTH and the antibody response $(75,76)$. It has been suggested that cytokines secreted by special subsets of $\mathrm{CD}^{+} \mathrm{T}$ cells ( $\mathrm{Th} 1$ and Th2) are involved. Cells belonging to the Th1 subset appear to be more susceptible to the induction of tolerance in vitro than Th2 cells (77) and Th1-mediated effector responses in vivo are more easily suppressed than those requiring Th2 cells (78). Thus, tolerance induced by feeding low doses of antigen would reflect the preferential activation of Th2 cells with subsequent downregulation of Th1-dependent, cell-mediated immune responses by Th2-derived cytokines such as IL-4 and IL-10 (79).

However, Garside et al. (80) claim that both $\mathrm{Th} 1$ and $\mathrm{Th} 2$ type responses are equally susceptible to high dose oral tolerance induction since oral administration of ovalbu$\min$ to BALB/c mice can suppress IFN- $\gamma$ as well as IL-4 production by peripheral lymph node cells. Moreover, an antigen-specific unresponsiveness state can be induced in IL$4^{-/-}$mice that have a defective $T h 2$ response. Russo et al. (81) also reported oral tolerance induction for a Th2 type response in an experimental model of asthma. The new murine model described consists of immunizing mice with small fragments of solidified hen egg white injected into the subcutaneous tissue. After challenge, the animals develop an intense and persistent lung eosinophilia and histopathological findings that resemble human asthma. Mice treated by the oral route before immunization showed a 
Figure 2 - Oral tolerance drastically reduces the magnitude of anti-ovalbumin (Ova) immune responses, but preserves the isotypic profile of the antibodies formed. Mice were treated as described in the legend to Figure 1. The numbers above the pies denote the global ELISA score for the group. Each section of the pie represents the percentage of each isotype in the overall antibody titer. Note that $\lg \mathrm{G} 1$ and $\lg \mathrm{G} 2 \mathrm{a}$ antibodies are equally suppressed in the tolerant group.

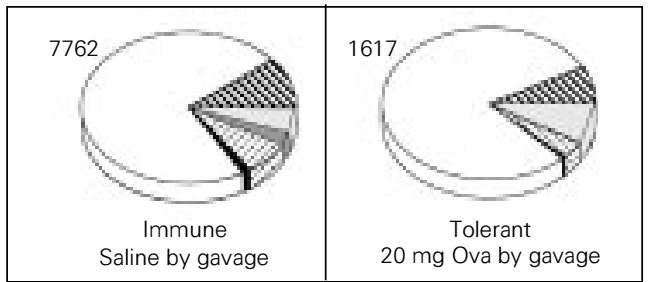

$\$ \lg M \square \lg 1 \quad \mathbf{a} \lg 2 \mathrm{a} \quad 8 \lg 2 \mathrm{~b} \quad \square \lg 3 \quad \square \lg A$

decrease in eosinophilic infiltration in the lungs as well as in serum IgE and IgG1 antibody production.

The present results support the data published by Garside et al. (80). If differential activation of Th2 clones occurred during oral tolerance induction, it would imply a selective suppression of the IgG2a isotype and a change in the pattern of anti-Ova antibodies produced by tolerant mice. However, as shown in Figure 2, the isotypic patterns of anti-Ova antibodies in 8-week-old tolerant and immune mice are the same, indicating that $\operatorname{IgG} 1$ and $\operatorname{IgG} 2 \mathrm{a}$ are both suppressed in mice rendered tolerant by gavage with a high dose of antigen. The same result is illustrated in Figure 3 where mice rendered tolerant when young maintain their tolerant state and, in addition, show a similar isotypic pattern of anti-Ova antibodies when challenged with Ova when old. In the 70-week-old immune control group, the anti-Ova antibody titers continued to be higher throughout the experiment (about one year) and they still consisted predominantly of IgG1. After all challenges (Figure 3), normal and immune mice kept their isotypic patterns but, in the tolerant group, there was a dramatic change in the isotypic pattern of anti-Ova antibodies. A shift in the proportion of antibodies produced from IgM to IgG (IgG1, IgG2a, IgG2b, IgG3) and IgA occurred in this group. Therefore, after challenge, although tolerant mice presented a low titer of anti-Ova antibodies, their isotypic pattern was similar to that of the immune control group. These data indicate that tolerance maintenance as well as its induction result in the suppression of all isotypes.

In conclusion, the data presented here do not support the hypothesis of a differential activation of cells belonging to the Th2 subset as a mechanism to induce the suppression described in oral tolerance experiments, nor do they support the idea of a subtractive process such as anergy or deletion. They indicate, on the contrary, that an active mechanism must be involved in oral tolerance induction and, although an activation of Th2 cells cannot be regarded as a mechanism, they do not rule out the possibility of regulatory cells being triggered by antigen feeding. The ways by which these regulatory cells would induce suppression might involve both idiotypic interaction and cytokine release. There are some reports on the secretion of cytokines such as GM-CSF and IFN- $\gamma$ by mesenteric lymph node cells from mice fed ovalbumin $24 \mathrm{~h}$ before (82). It has also been shown that oral tolerance to myelin basic protein in rats is due to activation of $\mathrm{CD} 8^{+} \mathrm{T}$ cells which down-regulate Th-cell function through the release of TGF- $\beta(74,83)$. Many reports also indicate that idiotypic connectivity is involved in tolerance induction.

Mechanisms of tolerance/aging and idiotypic connectivity

There are a series of experiments disproving the idea that immunological tolerance is a negative process. For instance, in mice made tolerant to allografts during the neonatal period, the suppressed alloreactive lymphocytes belong to a population of large activated lymphocytes (53). This possibility also applies to self-tolerance $(84,85)$, suggesting that tolerance depends on the addition of certain types of activated lymphocytes rather than on their subtraction.

If the development of oral tolerance is similar to tolerance to self components, it 
might depend on the inclusion of specific activated lymphocyte precursors into selfmaintained idiotypic lymphocyte circuits. In young animals, these endogenous circuits would be plastic enough to change upon contact with new elements in the diet. In this case, plasticity may depend on the use of $\mathrm{V}$ gene families which allow a loose connectivity of the lymphocytes (68). In older animals, tighter connections resulting from immunological experience would be a hindrance to this plasticity. Mouse strains which display abnormal patterns of idiotypic connectivity when young are susceptible to autoimmune defects and tend to be refractory to oral tolerance induction $(12,15,37,84)$. Aging is associated with a progressive decline in antibody responsiveness (see Figure 1) to foreign antigens, such as bacterial proteins, and SRBC, paralleled by a progressive rise in the production of self-reactive (auto) antibodies $(67,86,87)$. According to Weksler et al. (67), most of the auto-antibodies produced by old mice react with each other and their rise with aging results, at least in part, in an increased connectivity of the immune system. Studies on the auto-anti-idiotypic antibody response in young and old mice support this hypothesis $(84,88,89)$, indicating that aging represents a cross-wiring of the reactivities within the system and, consequently, an inevitable loss of ability to react with novel antigens.

Therefore, changes in immune activity with aging may be related to changes in the patterns of idiotypic connectivity among lymphocytes. Our results are consistent with this hypothesis. Both oral tolerance and immunization against a novel antigen are impaired in old mice (Figure 1) whereas the maintenance of these two kinds of immune activities is preserved for antigens already presented to the animal in early life (Table 1). Possibly, induction of oral tolerance requires incorporation of novelty into the dynamics of the immune system whereas its mainte-

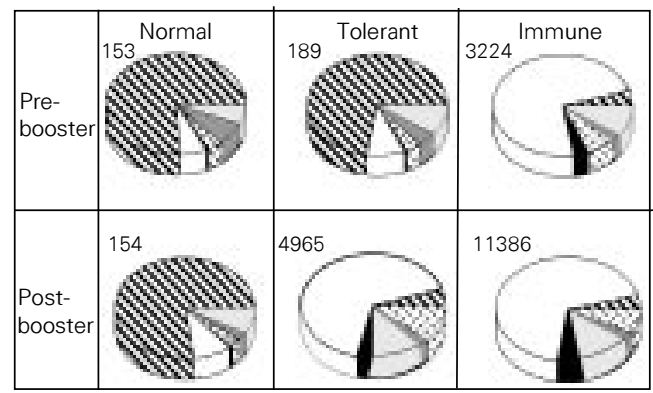

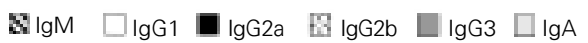

nance represents the recursion of already established circuits.

Oral tolerance and the rate of antigen intake

A factor known to be important for the establishment of oral tolerance is the rate of antigen intake. The most efficient way to induce oral tolerance is the continuous administration of the antigen at small doses. Experiments in mice (10) and guinea pigs (23) demonstrated that ingestion of Ova for several consecutive days was able to suppress the delayed hypersensitivity and serum antibody responses to a subsequent injection of the antigen in complete Freund's adjuvant. On the other hand, the animals were anaphylactically sensitized if the antigen was introduced in their diet all at once.

According to Stokes et al. (90), tolerance induction is related to a gradual and continuous absorption of the antigen. These authors showed that administration of $25 \mathrm{mg}$ Ova to $\mathrm{CBA}$ and SWR/J mice by the intragastric route for 14 days did not induce tolerance but if the antigen was voluntarily ingested throughout the day in the same amounts, the animals could be rendered tolerant. Thus, continuous contact with the antigen appears to be necessary to trigger the tolerance circuits.

We tested oral tolerance induction by two different protocols: a single gavage of $20 \mathrm{mg}$ Ova or voluntary ingestion of $4 \mathrm{mg} / \mathrm{ml}$
Figure 3 - Isotypic pattern of antiOva antibodies in 70-week-old mice orally treated when 8 weeks old and boosted after 52 weeks. Mice were treated as described in the legend to Table 1. The numbers above the pies denote the global ELISA score of the groups. Note that the isotypic profile of tolerant mice is closer to that of normal mice before the booster and resembles the profile of the immune group after the booster. 
Figure 4 - Voluntary ingestion of antigen on consecutive days is more effective than a single gavage for oral tolerance induction. B6D2F1 mice of different ages were treated either by a single gavage administration of $20 \mathrm{mg}$ ovalbumin (Ova) or by voluntary ingestion of a solution of $4 \mathrm{mg} /$ $\mathrm{ml}$ Ova in drinking water for 5 to 10 days. The animals were immunized 7 days after the last oral treatment and boosted 14 days thereafter. ELISA scores and significance were calculated as described in the legend to Figure 1. Only 8-week-old $(P<0.001)$ and 25-week-old mice $(P<0.025)$ could be made tolerant by a single gavage administration of Ova, whereas voluntary ingestion was effective for all groups treated with Ova $(P<0.001)$.

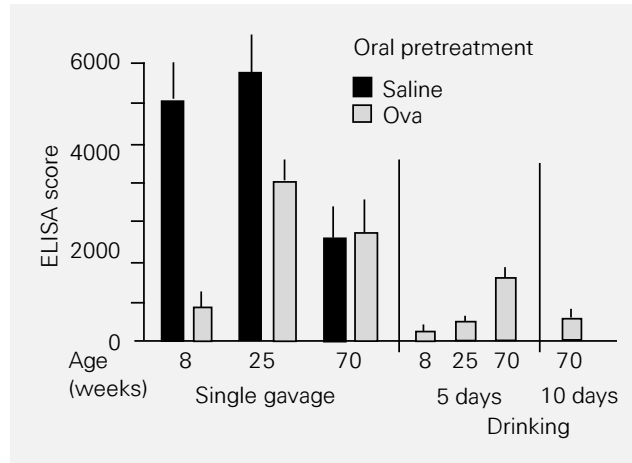

Ova solution for 5 or 10 days (the normal daily drinking volume of a mouse is approximately $5 \mathrm{ml}$, so the animals ingest approximately $20 \mathrm{mg}$ Ova per day). As expected, 5day voluntary ingestion of Ova was significantly more efficient for oral tolerance induction than a single feeding of $20 \mathrm{mg}$ Ova (Figure 4). In 8-week-old B6D2F1 mice, both protocols were highly effective in inducing oral tolerance but the serum antibody titers after voluntary ingestion of Ova were even lower than after the single feeding protocol. Voluntary ingestion of Ova for 5 days induced tolerance in 25-week-old B6D2F1 mice whereas a single feeding procedure did not. Furthermore, 70-week-old B6D2F1 mice, which are totally refractory to oral tolerance induction by a single gavage of Ova (Figure 1), can be rendered tolerant by voluntary ingestion of Ova. Ingestion for 5 days resulted in moderate suppression and ingestion for 10 days was highly effective.

Different antigen-presenting cells and cytokines may be triggered by different ways of antigen ingestion

The difference between the two protocols may be due to the way the antigen is processed and presented by mucosal antigen-presenting cells (APC). The first and obvious distinction is the antigen loading. When a high dose of antigen enters the mucosal lymphoid tissue at once, probably all APC available are recruited to process and present the protein, whereas when the same amount of protein is gradually administered in small doses, only the most efficient APC (dendritic cells) are mobilized. This differential presentation may trigger different pathways of $T$ cell activation resulting, for instance, in a distinct profile of cytokine release.

Alternatively, the two protocols may lead to a distinct degree of antigen luminal digestion. In a voluntary ingestion regimen, antigen administered in continuous small amounts would be more exposed to digestive enzymes present in the intestinal lumen than a large amount of protein fed as a bolus. The result of a more extensive luminal processing of antigen may be a decrease in the requirements for processing by $\mathrm{APC}$ in the gut and differences in $T$ cell responses, inasmuch as different epitopes may be displayed.

Several groups have recently focused on APC in the gut as potential regulators of mucosal immune responses. There are a number of cell types that can process and present antigens in the intestinal lymphoid tissue: macrophages, dendritic cells, B cells present in Peyer's patches and lamina propria as well as the intestinal epithelial cells $(91,92)$. Antigen-presenting cells in the lamina propria and Peyer's patches use the classical class I or class II presentation pathway depending on whether the antigen gains access to the cytoplasm or to the endosomic compartments of the cell (93). Intestinal epithelial cells, however, seem to take up soluble antigens and transport them by the endolysosomal route but they do not use class II MHC as restriction elements for peptide presentation. Instead, products of antigen processing within gut epithelial cells seem to associate with CD1b molecules and the antigen presentation process is very inefficient (94). The preferential subpopulation of $\mathrm{T}$ cells activated by these APC are $\mathrm{CD}^{+}(95)$ although it is not clear yet which other molecules are involved in cell-to-cell interactions. Therefore, several data support the idea that antigen presentation in gut lymphoid tissue may 
have unusual characteristics depending on the way the antigen is absorbed (95).

Our hypothesis that antigen uptake by voluntary ingestion would result in recruitment of APC distinct from that triggered by single gavage was tested in two experiments. First, we measured the isotypic profile of the anti-Ova antibodies induced in tolerant mice by the two protocols assuming that B cells become committed to producing different isotypes depending on the cytokines released by T helper cells. On the other hand, T-cell commitment to patterns of cytokine secretion could be altered by the way these cells are activated by different antigen-presenting cells. Second, we tested a protocol of tolerance induction using intravenous (iv) injection of Ova cleaved by cyanogen bromide (CNBr-Ova) and measured the isotypic profile of antibodies produced by this protocol. This alternative iv procedure was designed to investigate the role of previous digestion of antigen in tolerance induction.

Figure 5 shows the isotypic pattern of anti-Ova antibodies in 8-week-old mice treated by the oral route with a single gavage of saline, a daily gavage of $20 \mathrm{mg}$ Ova or voluntary ingestion of $4 \mathrm{mg} / \mathrm{ml}$ Ova in water for 5 days. All mice were challenged with Ova in adjuvant 7 days after the last oral exposure and sera for antibody testing were collected 7 days after the booster. As previously shown in Figure 2, oral tolerance induction by a single gavage induced a suppression of all isotypes. However, the voluntary ingestion protocol resulted in differential suppression of IgG1 and a compensatory increase in the proportion of IgM antibodies. These results suggest not only that continuous feeding is a more efficient protocol for oral tolerance induction, but also that it triggers different pathways of $\mathrm{T}$ and $\mathrm{B}$ cell activation.

Observing the low levels of anti-Ova antibodies induced in mice made tolerant by voluntary ingestion of Ova, one can argue that the antibody titers are so low that they

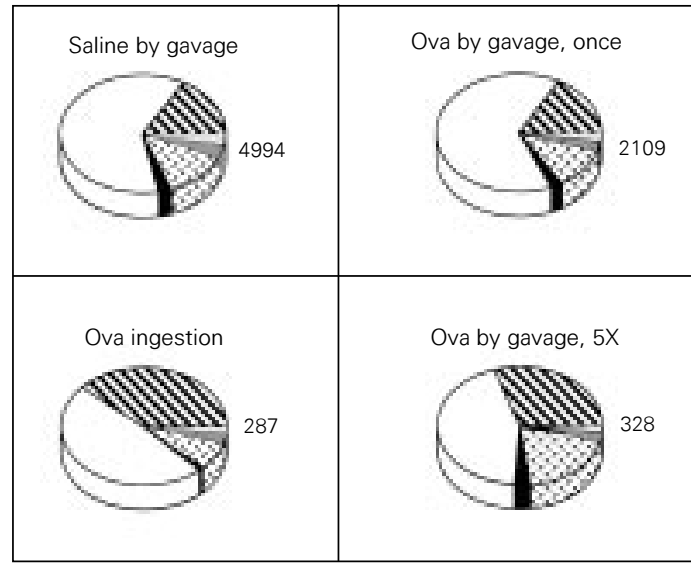

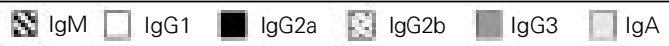

represent only natural IgM antibodies present in normal serum and that the isotypic profile simply shows the total absence of $B$ cell activation by ovalbumin. In the following experiments, however, we confirm the present data under different conditions.

B6D2F1 mice injected iv with $500 \mu \mathrm{g}$ CNBr-Ova 7 days before ip immunization with Ova in adjuvant showed a significant decrease in anti-Ova antibody titers as compared to a control group injected iv with saline (Figure 6). On the other hand, iv injection of the same dose of native ovalbumin did not suppress the immunization to the protein. This result indicates that cleavage of the antigen, such as the degradation of proteins in the intestine, may have an important role in tolerance induction.

Curiously, the isotypic pattern of antiOva antibodies from mice rendered tolerant by iv injection of CNBr-Ova shown in Figure 6 is closely similar to the voluntaryingestion-tolerance pattern. There is a clear suppression of IgG1 antibodies and a relative increase in IgM levels. Mice made tolerant by a single gavage of $20 \mathrm{mg}$ Ova again show suppression of all isotypes as compared to the control immune group. Injection of $500 \mu \mathrm{g}$ Ova iv did not induce tolerance but triggered a change in the pattern of antibodies produced.

The levels of serum antibodies in mice
Figure 5 - Mice treated by gavage and voluntary ingestion of ovalbumin (Ova) show a different pattern of suppression of their anti-Ova immune response. B6D2F1 mice at 8 weeks of age were treated with either salinene by gavage, one gavage of $20 \mathrm{mg}$ Ova, voluntary ingestion of 4 $\mathrm{mg} / \mathrm{ml}$ Ova for 5 days, or 5 consecutive daily gavages of 20 mg Ova. All mice were immunized as described in the legend to Figure 1. All oral treatments induced oral tolerance $(P<0.001)$ while voluntary ingestion and 5 gavages of Ova induced a preferential suppression of lgG. 
Figure 6 - Previous cleavage of the antigen influences tolerance induction. Eight-week-old B6D2 F1 mice were treated with 20 mg ovalbumin (Ova) by gavage or by intravenous injection of $500 \mu \mathrm{g}$ native Ova or $500 \mu \mathrm{g}$ of cyanogen bromide-treated Ova (CNBr-Ova) 7 days before ip immunization. All mice were immunized as described in the legend to Figure 1. The numbers above the pies indicate the global ELISA score of each group. Both oral treatment with Ova and iv injection of $\mathrm{CNBr}-\mathrm{O} v a$ induced oral tolerance $(P<0.001)$ but cleavage of the antigen led to a preferential suppression of $\lg G$.

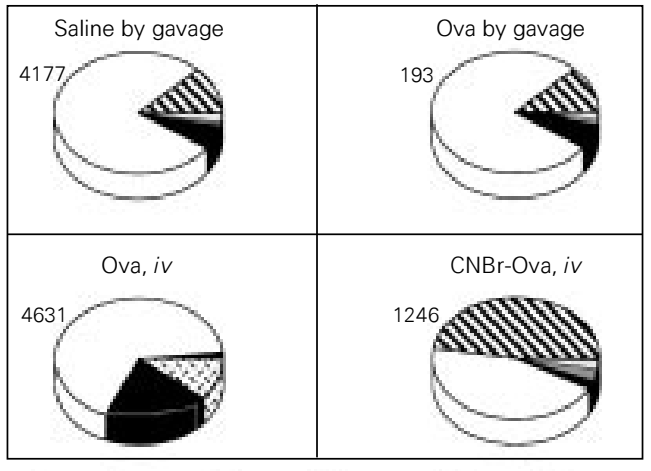

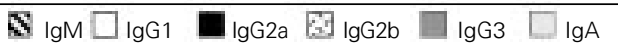

rendered tolerant by iv injection of $\mathrm{CNBr}$ Ova shown in Figure 6 are not as low as those illustrated in Figure 4, although we observed an equivalent alteration in the isotype profile. This result suggests that an interference with the presentation of antigen, in this case by its cleavage, may result in a different activation of the $B$ cells reactive to the antigen. It also reinforces the possibility that the isotypic changes triggered by the voluntary ingestion protocol (Figure 5) do not represent a numerical artifact.

Therefore, our data indicate that the rate of antigenic intake could alter not only the efficiency but also the pathway of tolerance induction. In addition, the experiments reported here suggest that both the loading of APC and the partial digestion of the antigen are plausible hypotheses to explain the efficiency of the voluntary ingestion protocol.

Experiments performed with slow intravenous antigen infusion indicate that the rate of antigenic entry into the circulation per se is neither relevant for the efficiency nor determinant for the occurrence of oral tolerance. Using Harvard infusion pumps and Alzet osmotic pumps, which deliver antigen iv for $1 \mathrm{~h}$ and ip for $24 \mathrm{~h}$, respectively, Stransky $(96,97)$ demonstrated that slow parenteral infusion of Ova is not sufficient to induce tolerance in 8-week-old B6D2F1 mice. We were thus left with the hypothesis that the rate of antigen entry was a fundamental requirement in the oral route. Con- tact through mucosal tissues may involve other important factors such as previous digestion of the antigen, interaction with several lymphoid and non-lymphoid populations only present there, typical cytokines, and a number of other unique molecules about which little information is available.

In order to test this hypothesis, we designed a protocol comparing voluntary ingestion of ovalbumin and consecutive gavages as regimens for oral tolerance induction in susceptible B6D2F1 mice. Animals were treated for 5 consecutive days either by a daily gavage of $20 \mathrm{mg}$ Ova or by voluntary ingestion of $4 \mathrm{mg} / \mathrm{ml}$ Ova in their drinking water. We analyzed the efficiency of these treatments in inducing oral tolerance and the isotypic profile of antibodies produced always comparing them with the single gavage protocol.

Figure 5 shows that, at least for young mice, 5 daily consecutive gavages are as efficient as voluntary ingestion of the same dose of ovalbumin for 5 days for oral tolerance induction as compared to the single gavage protocol. Further experiments, using old mice, will help elucidate whether repeated gavages would be able to replace continuous feeding as an efficient method to induce oral tolerance in these refractory animals.

The isotypic profile of anti-Ova antibodies induced by a 5 -gavage protocol is shown in Figure 5 along with the profiles of voluntary ingestion, single gavage and saline protocols. The pattern of isotypes induced by the 5-gavage protocol is similar to that induced by the voluntary ingestion regimen.

Results from these last experiments demonstrate that, in young mice, a multiple feeding protocol leads to a suppression comparable to that achieved by a continuous feeding of the same antigen.

We know from previous studies in adult and old mice $(12,32)$ that intermittent exposures to an antigen by oral route do not induce tolerance but may lead to systemic 
immunization. On the other hand, consecutive contacts with the same dose of antigen do not induce oral immunization. Therefore, episodic oral exposures appeared to be ideal for oral immunization whereas both repetitive and continuous oral contacts with a protein, such as in our daily meals, are sufficient to trigger the circuits responsible for oral tolerance induction.

The cellular and molecular components involved in the suppression observed as the oral tolerance phenomenon probably depend on reiterated stimulation, either because their action is of short duration (such as cytokine activities) or because they are quickly renewed (such as surface molecules).

\section{Conclusion}

The formation of antibodies as well as the class of immunoglobulin produced is a process dependent on $T$ cell stimulation of the B cells. A large amount of evidence indicate that the B-T cell interaction and cytokines released by $\mathrm{T}$ cells are determinant for the immunoglobulin class switch (98-100). Since we were using the suppression of specific antibody production as a parameter for studying oral tolerance, we decided to analyze the isotypic patterns under distinct experimental conditions as a way to assess the influence of age and rate of antigen intake on the interactions between $B$ and $T$ cells during oral tolerance establishment. We demonstrated here that oral tolerance is an active phenomenon influenced by other natural events such as aging and conditions of antigen feeding. Senescence is associated with a decrease in susceptibility to oral tolerance induction but does not affect oral tolerance maintenance. On the other hand, both previous cleavage of the antigen and repeated oral exposures seem to favor the establishment of oral tolerance. These factors affect not only the susceptibility to oral tolerance induction but also the pathways of $B$ and $T$ cell interactions that lead to antibody production.

\section{Acknowledgments}

We thank Mrs. Ilda Marsal de Souza for competent care of the animal colonies and Ms. Frankcinéia Aparecida de Assis and Ms. Ilma Marsal de Souza for technical assistance. We also thank Valéria Ruiz de Souza for help with editing this text.

\section{References}

1. Witthum-Hudson JA, An L-L, Saltzman WM, Prendergast RA \& MacDonald $A B$ (1996). Oral immunization with an antiidiotypic antibody to the exoglycolipid antigen protects against experimental Chlamydia trachomatisinfection. Nature Medicine, 2: 1116-1121.

2. Hemmings WA (1978). Antigen Absorption by the Gut. MTP Press, Lancaster.

3. Husband AJ \& Gowans JL (1978). The origin and antigen-dependent distribution of IgA-containing cells in the intestine. Journal of Experimental Medicine, 148: 1146-1151.

4. McDermont M \& Bienenstock J (1979). Evidence for a common mucosal immunological system. Journal of Immunology, 122: 1892-1898

5. Bienenstock J, McDermont M \& Befus
AD (1979). A common mucosal immune system. In: Ogra PL \& Dayton D (Editors), Immunology of Breast Milk. Raven Press, New York.

6. Koster FT \& Pierce NF (1983). Parenteral immunization causes antigen-specific cellmediated suppression of an intestinal lgA response. Journal of Immunology, 131: 115-118.

7. Mowat AM (1987). The regulation of immune responses to dietary proteins. Immunology Today, 8: 93-98.

8. Vaz NM \& Carvalho CR (1994). Assimilation, tolerance and the end of innocence. Ciência e Cultura, 46: 351-357.

9. Hanson DG (1980). Ontogeny of orallyinduced tolerance to soluble proteins in mice. I. Priming and tolerance in newborns. Journal of Immunology, 127: 1518-1524.
10. Saklayen MG, Pesce AJ, Pollak VE \& Michael JG (1984). Kinetics of oral tolerance: study of variables affecting tolerance induced by oral administration of antigen. International Archives of Allergy and Applied Immunology, 73: 5-9.

11. Vaz NM, Rios MJC, Lopes LM, Gontijo CM, Castanheira EB, Jacquemart F \& Andrade LAB (1987). Genetics of susceptibility to oral tolerance to ovalbumin. Brazilian Journal of Medical and Biological Research, 20: 785-790.

12. Faria AMC, Garcia G, Rios MJC, Michalaros CL \& Vaz NM (1993). Decrease in susceptibility to oral tolerance induction and occurrence of oral immunization to ovalbumin in 20-38-week-old mice. The effect of interval between oral exposures and rate of antigen intake in the oral im- 
munization. Immunology, 78: 147-151.

13. Peng H-J, Turner MW \& Strobel S (1989). The kinetics of oral hyposensitization to a protein antigen are determined by immune status and the timing, dose and frequency of antigen administration. Immunology, 67: 425-430.

14. Mowat AM, Lamont AG \& Bruce MG (1987). A genetically determined lack of oral tolerance to ovalbumin is due to failure of the immune system to respond to intestinally-derived tolerogen. European Journal of Immunology, 17: 1673-1676.

15. Rios MJC, Pereira MAC, Lopes LM, Faria AMC, Gontijo CM, Castanheira EB \& Vaz NM (1988). Tolerance induction and immunological priming initiated by mucosal contacts with protein antigens in inbred strains of mice. Brazilian Journal of Medical and Biological Research, 21: 825-831.

16. Faria AMC, Ficker SM, Rodrigues VS \& Vaz NM (1995). Oral tolerance induction by gavage or by voluntary intake of antigen results in different patterns of isotype suppression. IV Latin American Congress of Immunology, ALAl, Mexico, M025.

17. Wells HG (1911). Studies on the chemistry of anaphylaxis. III. Experiments with isolated proteins, especially those of the hen's egg. Journal of Infectious Diseases, 9: 147-156.

18. Thomas HC \& Parrot DV (1974). The induction of tolerance to a soluble protein antigen by oral administration. Immunology, 27: 631-639.

19. Vaz NM, Maia LCS, Hanson DG \& Lynch JM (1977). Inhibition of homocytotropic antibody responses in adult mice by previous feeding with the specific antigen. Journal of Allergy and Clinical Immunology, 60: 110-115.

20. Richman LK, Chiller JM, Brown WR, Hanson DG \& Vaz NM (1978). Entericallyinduced immunological tolerance. I. Induction of suppressor $T$ cells by intragastric administration of soluble proteins. Journal of Immunology, 212: 2429-2435.

21. Dolezel J \& Bienenstock J (1971). Immune response of the hamster to oral and parenteral immunization. Cellular Immunology, 2: 54-60.

22. Stokes CR \& Swarbrick ET (1977). Induction of tolerance after oral feeding of soluble antigen. Biochemical Society Transactions, 5: 1573-1580.

23. Heppel JML \& Kilshaw JP (1982). Immune responses of guinea pigs to dietary protein. I. Induction of tolerance by feeding with ovalbumin. International Archives of Allergy and Applied Immunology, 68: 5459 .
24. Wicher V \& Wicher K (1986). Immune responses of rabbits to intrarectal injections of particulate and soluble antigens with and without enemas. Clinical Immunology and Immunopathology, 41: 443452.

25. Husby S, Mestecky J, Moldoveanu Z, Holland S \& Elson CO (1994). Oral tolerance in humans. Journal of Immunology, 152: 4663-4669.

26. Strobel S \& Ferguson A (1987). Persistence of oral tolerance in mice fed ovalbumin is different for humoral and cell-mediated immunity. Immunology, 60: 317-322.

27. Maia LCS, Vaz NM \& Vaz EM (1974). Effect of soluble antigen on lgE responses in the mouse. International Archives of Allergy and Applied Immunology, 46: 339346.

28. Bruce MG \& Ferguson A (1986). The influence of intestinal processing on the immunogenicity and molecular size of absorbed, circulating ovalbumin in mice. Immunology, 59: 295-300.

29. Hanson DG, Vaz NM, Rawlings LA \& Lynch JL (1979). Inhibition of specific immune responses by feeding protein antigens. II. Effects of prior passive and active immunization. Journal of Immunology, 122: 2261-2266.

30. Strobel S, Mowat AM, Drummond HE \& Ferguson A (1981). Age at first feed influences the immune responses to fed antigens in mice. Pediatric Research, 15: 1193-1199.

31. Peng H-J, Turner MW \& Strobel S (1989). Failure to induce oral tolerance to protein antigens in neonatal mice can be corrected by transfer of adult spleen cells. Pediatric Research, 26: 486-490.

32. Verdolin BA, Faria AMC, Carvalho $C R$, Lahmann WM \& Vaz NM (1993). Systemic immunization of mature mice by the oral route. Brazilian Journal of Medical and Biological Research, 26: 725-734.

33. Vaz NM, Faria AMC, Verdolin BA \& Carvalho CR (1997). Immaturity, ageing and oral tolerance. Scandinavian Journal of Immunology, 46: 225-229.

34. Moreau M-C \& Gaboriau-Routhiau V (1996). The absence of gut flora, the doses of antigen ingested and aging affect the long-term peripheral tolerance induced by ovalbumin feeding in mice. Research in Immunology, 147: 49-59.

35. Habicht GS (1980). Tolerance to human IgG in aged C57BL/6 and Balb/c mice. Federation Proceedings, 39: 2118-2124.

36. Weigle WO, Thoman ML \& Goodman MG (1988). The effect of aging on the induction of tolerance in a subpopulation of $B$ lymphocytes. Clinical Immunology, 111: 253-257.

37. Staples PJ \& Talal N (1969). Relative inability to induce tolerance in adult NZB and (NZB X NZW) F1 mice. Journal of Experimental Medicine, 130: 123-130

38. Doken J, Weksler ME \& Siskind GW (1980). Effect of age on ease of B-cell tolerance induction. Cellular Immunology, 55: 66-73

39. Dekkruyff RH, Kan EAR, Weksler ME \& Siskind GW (1980). Effect of aging on T cell tolerance induction. Cellular Immunology, 56: 58-67.

40. Wei J, Xu H, Davies JL \& Hemmings GP (1992). Increase of plasma IL-6 concentration with age in healthy subjects. Life Sciences, 51: 1953-1956.

41. Daynes RA \& Araneo BA (1992). Prevention and reversal of age-associated changes in immunologic responses by supplemental dehydroepiandrosterone sulfate therapy. Immunology and Infectious Diseases, 3: 135-154.

42. Daynes RA, Araneo BA, Ershler WB, Maloney C \& Li G-Z (1993). Altered regulation of IL-6 production with normal aging. Journal of Immunology, 150: 52195230

43. Araneo BA, Woods II ML \& Daynes RA (1993). Reversal of the immunosenescent phenotype by dehydroepiandrosterone: hormone treatment provides an adjuvant effect on the immunization of aged mice with recombinant hepatitis B surface antigen. Journal of Infectious Diseases, 167: 830-840.

44. Inamizu T, Chang M-P \& Makinodan $T$ (1985). Influence of age on the production and regulation of interleukin 1 in mice. Immunology, 55: 447-455.

45. Buckler AJ, Vie H, Sonenshein GE \& Miller RA (1988). Defective T lymphocytes in old mice. Diminished production of mature c-myc RNA after mitogen exposure not attributable to alterations in transcription or RNA stability. Journal of Immunology, 140: 2442-2446.

46. Thoman ML \& Weigle WO (1989). The cellular and subcellular bases of immunosenescence. Advances in Immunology, 46: 221-261.

47. Ernest DN, Weigle WO, McQuitty DN, Rothermel AL \& Hobbs MV (1989). Stimulation of murine $T$ cell subsets with antiCD3 antibody. Age-related defects in the expression of early activation molecules. Journal of Immunology, 142: 1413-1421.

48. Philosophe B \& Miller RA (1990). Diminished calcium signal generation in subsets of $T$ lymphocytes that predominate 
in old mice. Journal of Gerontology, 45: B87-B93.

49. Senda S, Cheng E \& Kawanishi H (1988). Aging-associated changes in murine intestinal immunoglobulin $\mathrm{A}$ and $\mathrm{M}$ secretions. Scandinavian Journal of Immunology, 27: 157-164

50. Kawanishi H, Senda S \& Ajitsu S (1989). Aging-associated intrinsic defects in IgA production by murine Peyer's patch $B$ cells stimulated by autoreactive Peyer's patch $T$ cell hybridoma-derived $B$ cell stimulatory factors (BSF). Mechanisms of Ageing and Development, 49: 61-78.

51. Owen RD (1945). Immunogenetic consequences of vascular anastomosis between bovine twins. Science, 102: 400403.

52. Burnet MF (1959). The Clonal Selection Theory of Immunity. 1st edn. The Vanderbilt and Cambridge University Presses, Nashville/London.

53. Bandeira A, Carnaud C, Coutinho A, Jacquemart F \& Forni L (1989). Transplantation tolerance correlates with high levels of lymphocyte activity. Proceedings of the National Academy of Sciences, USA, 86: $272-276$

54. Hanson DG \& Morimoto $T$ (1980). A role of digestion in orally induced tolerance to ovalbumin. Journal of Allergy and Clinical Immunology, 65: 227-228.

55. Hanson DG \& Morimoto $T$ (1987). Delayed recovery of orally-induced tolerance to proteins in irradiated and spleen-cell reconstituted mice. Advances in Experimental Medicine and Biology, 216A: 733738.

56. Strobel S (1996). Neonatal oral tolerance. Annals of the New York Academy of Sciences, 778: 88-102.

57. Ramsdell F \& Fowlkes BJ (1990). Clonal deletion versus clonal anergy: the role of the thymus in inducing self tolerance. Science, 248: 1342-1344.

58. Schwartz RH (1990). A cell culture model for T lymphocyte clonal anergy. Science, 248: 1349-1352

59. Jenkins MK \& Schwartz RH (1987). Antigen presentation by chemically-modified splenocytes induces antigen-specific $T$ cell unresponsiveness in vitro and in vivo. Journal of Experimental Medicine, 165: 302-308

60. Quill H \& Schwartz RH (1987). Stimulation of normal inducer $T$ cell clones with antigen presented by purified la molecules in planar lipid membranes: specific induction of a long-lived state of proliferative nonresponsiveness. Journal of Immunology, 138: 3704-3708.
61. Mueller DL, Jenkins MK \& Schwartz RH (1989). An accessory cell-derived costimulatory signal acts independently of protein kinase $\mathrm{C}$ activation to allow $\mathrm{T}$ cell proliferation and prevent the induction of unresponsiveness. Journal of Immunology, 142: 2617-2622.

62. Jenkins MK, Chen C, Jung G, Mueller DL \& Schwartz RH (1990). Inhibition of antigen-specific proliferation of type 1 murine T cell clones after stimulation with immobilized anti-CD3 monoclonal antibody. Journal of Immunology, 144: 16-21.

63. Weiner $\mathrm{HL}$, Friedman A, Miller A, Khoury SJ, Al-Sabbagh A, Santos L, Sayegh M, Nussenblatt RB, Trentham DE \& Hafler DA (1994). Oral tolerance: immunologic mechanisms and treatment of animal and human organ-specific autoimmune diseases by oral administration of autoantigens. Annual Review of Immunology, 12: 809-837.

64. Whitacre CC, Gienapp IE, Orosz CG \& Bitar DM (1991). Oral tolerance in experimental autoimmune encephalomyelites. III. Evidence for clonal anergy. Journal of Immunology, 147: 2155-2163.

65. Melamed D \& Friedman A (1994). In vivo tolerization of Th1 lymphocytes following a single feeding with ovalbumin: anergy in the absence of suppression. European Journal of Immunology, 24: 1974-1981.

66. Lahmann W, Menezes JS, Verdolin BA \& Vaz NM (1992). Influence of age on the induction of oral tolerance in mice and its adoptive transfer by spleen cells. Brazilian Journal of Medical and Biological Research, 25: 813-821.

67. Weksler ME, Russo C \& Siskind GW (1989). Peripheral T cells select the B-cell repertoire in old mice. Immunological Reviews, 110: 173-185.

68. Carlsson L \& Holmberg D (1990). Genetic basis of the neonatal antibody network: high connectivity correlates with limited $\mathrm{N}$-region diversity and germ-line $\mathrm{V}$-gene expression. International Immunology, 2: 639-643.

69. Faria AMC, Ficker SM, Rodrigues VS, Lahman WM \& Vaz NM (1995). Antigen feeding induces oral tolerance in young mice and changes the isotype of immune response in old mice. Clinical Immunology and Immunopathology, 76: S110 (Abstract).

70. Mattingly JA \& Waksman BH (1978). Immunologic suppression after oral administration of antigen. I. Specific suppressor cells formed in rat Peyer's patches after oral administration of sheep erythrocytes and their systemic migration. Journal of
Immunology, 121: 1878-1883.

71. Ngan J \& Kind LS (1978). Suppressor T cells for IgE and IgG in Peyer's patches of mice made tolerant by the oral administration of ovalbumin. Journal of Immunology, 120: 861-865.

72. Mowat AM (1985). The role of antigen recognition and suppressor cells in mice with oral tolerance to ovalbumin. Immunology, 56: 253-257.

73. McMenamin C \& Holt PG (1993). The natural immune response to inhaled soluble protein antigens involves major histocompatibility complex (MHC) class-Irestricted $\mathrm{CD} 8+\mathrm{T}$ cell-mediated but $\mathrm{MHC}$ class II-restricted CD4+ $\mathrm{T}$ cell dependent immune deviation resulting in selective suppression of immunoglobulin E production. Journal of Experimental Medicine 178: 889-893.

74. Miller A, Lider O, Roberts AB, Sporn MB \& Weiner HL (1992). Suppressor T cells generated by oral tolerization to myelin basic protein suppress both in vivo and in vitro immune response by the release of transforming growth factor beta after antigen-specific triggering. Proceedings of the National Academy of Sciences, USA, 89: 421-425.

75. Barone KS, Jain SL \& Michael JG (1995). Effect of in vivo depletion of $\mathrm{CD}^{+}$and $\mathrm{CD}^{+}$cells on the induction and maintenance of oral tolerance. Cellular Immunology, 163: 19-29.

76. Garside P, Steel M, Liew FY \& Mowat AM (1995). CD4 ${ }^{+}$but not $\mathrm{CD}^{+} \mathrm{T}$ cells are required for the induction of oral tolerance. International Immunology, 7: 501504.

77. Williams ME, Lichtman $A H$ \& Abbas $A K$ (1990). Anti-CD3 antibody induces unresponsiveness to IL-2 in Th-1 but not in Th-2 clones. Journal of Immunology, 144: 1208-1212.

78. Burstein $\mathrm{HJ}$, Shea $\mathrm{CM}$ \& Abbas $A K$ (1992). Aqueous antigens induce in vivo tolerance selectively in IL-2 and IFN- $\gamma$ producing (Th1) cells. Journal of Immunology, 148: 3687-3692.

79. Burstein HJ \& Abbas AK (1993). In vivo role of interleukin-4 in T cell tolerance induced by aqueous protein antigen. Journal of Experimental Medicine, 177: 457-461.

80. Garside P, Steel M, Worthey EA Satoskar A, Alexander J, Bluethmann $\mathrm{H}$ Liew FY \& Mowat AM (1995). T helper 2 cells are subject to high dose oral tolerance and are not essential for its induction. Journal of Immunology, 154: 56495655. 
81. Russo M, Jancar S, Siqueira ALP, Mello EAG, Mengel J, Ficker SM \& Faria AMC (1996). Oral tolerance prevents the development of experimental asthma. Immunology Letters (in press).

82. Hoyne GF, Callow MG, Kuhlman J \& Thomas WR (1993). T-cell lymphokine response to orally administered proteins during priming and unresponsiveness. Immunology, 78: 534-540.

83. Khoury SJ, Hancock WW \& Weiner HL (1992). Oral tolerance to myelin basic protein and natural recovery from experimental autoimmune encephalomyelites are associated with down-regulation of inflammatory cytokines and differential upregulation of transforming growth factor $B$, interleukin 4 , and prostaglandin $E$ expression in the brain. Journal of Experimental Medicine, 176: 1355-1364.

84. Dighiero G, Lim A, Poncet P, Daushik A, Ge XR \& Maxié J-C (1987). Age-related natural antibody specificities among hybridoma clones originating from NZB spleen. Immunology, 62: 341-347.

85. Bandeira A, Coutinho A, Martinez C \& Pereira P (1988). The origin of natural antibodies and the internal activity of the immune system. International Review of Immunology, 3: 47-58.

86. Paul JR \& Bunnel WW (1932). Anti-SRBC agglutinin with age. American Journal of Medical Sciences, 183: 90-94.

87. Roberts-Thomson IC, Whittinghom S, Youngchaiyud U \& Mackay IR (1968). Aging, immune response and mortality.
Lancet, II: 24-28.

88. Goidl EA, Thorbecke GJ, Weksler ME \& Siskind GW (1980). Production of autoanti-idiotypic antibody during the normal immune response: changes in the autoanti-idiotypic antibody response and idiotype repertoire associated with aging. Proceedings of the National Academy of Sciences, USA, 77: 6788-6793.

89. Huetz F, Tai Kom Y \& Coutinho A (1990). Cellular basis for the age-associated increase in autoimmune reactions. International Immunology, 2: 329-335.

90. Stokes CR, Swarbrick ET \& Soothill JF (1982). Genetic differences in immune exclusion and partial tolerance to ingested antigens. Clinical and Experimental Immunology, 53: 678-685.

91. Bland PW \& Kambarage DM (1991). Antigen handling by the epithelium and lamina propria macrophages. Gastroenterology Clinics of North America, 20: 310.

92. Panja A \& Mayer L (1994). Diversity and function of antigen presenting cells in mucosal sites. In: Ogra MELPL, McGhee JR, Mestecky J, Strober W \& Bienenstock J (Editors), Handbook of Mucosal Immunology. Academic Press, San Diego, CA.

93. Mayer L, So LP, Yio XY \& Small G (1996). Antigen trafficking in the intestine. In: Weiner WL \& Mayer LF (Editors), Oral Tolerance: Mechanisms and Applications. New York Academy of Sciences, New York
94. Panja A, Blumberg RS, Balk SP \& Mayer $L$ (1993). CD1b is involved in T cell:epithelial cell interactions. Journal of Experimental Medicine, 178: 1115-1120.

95. Mayer L \& Shlien R (1987). Evidence for function of an la molecule on gut epithelial cells in man. Journal of Experimental Medicine, 166: 1471-1478.

96. Stransky BFA (1996). As fases iniciais da tolerância oral. Master's thesis, Departamento de Bioquímica e Imunologia, UFMG, Belo Horizonte.

97. Stransky B, Lahmann WM, Faria AMC \& Vaz NM (1997). Concomitant parenteral exposure to antigen may block oral tolerance induction. Brazilian Journal of Medical and Biological Research (in press).

98. Coffman RL, Seymour BWP, Lebman DA, Hirak DD, Christiansen JA, Shrader B, Cherwinski HM, Savelkoul HFJ, Finkelman FD, Bond MW \& Mosmann TR (1988). The role of helper T cell products in mouse $B$ cell differentiation and isotype regulation. Immunological Reviews, 102: 5-28.

99. Esser C \& Radbruch A (1990). Immunoglobulin class switching: molecular and cellular analysis. Annual Review of Immunology, 8: 717-735.

100. Finkelman FD, Holmes J, Katona IM, Urban JFJ, Beckman MP, Park L, Schooley KA, Coffman RL, Mosmann T \& Paul W (1990). Lymphokine control of in vivo immunoglobulin isotype selection. Annual Review of Immunology, 8: 303333. 